DOI: 10.20472/TEC.2019.008.021

\author{
NEAL PETERSEN \\ North-West University, South Africa \\ JOSEF DE BEER \\ North-West University, South Africa
}

\title{
THE FOREST IN MY HAND: STUDENT TEACHERS' EXPERIENCES OF ENGAGING IN AN EDUCATIONAL EXCURSION
}

\begin{abstract}
:
This paper sheds light on the value of a three-day excursion for South African student teachers in their first year of study. The rationale for the excursion should be considered from two perspectives: the unfortunate history of the country that divided people along racial lines, and the poor quality of teaching and learning that characterizes many South African school classrooms. This context dictates innovative interventions in pre-service teacher education, in order to ensure that South Africa has teachers who are inclusive and who enhance social justice on the one hand, and on the other hand who are well educated in making use of learner-centred and inquiry learning approaches. South Africa is a young democracy, and the legacy of the apartheid regime is still seen in a society that is not completely integrated. The North-West University (NWU) has three campuses, and whereas the Mafikeng Campus hosts predominantly Black students, the Potchefstroom Campus again has mainly White students. When student teachers board the buses to take them to the venue where the excursion is held, they also enter a different epistemological learning space, where they will reflect on their journeys of becoming teachers in socially diverse groups. While navigating the learning space as homo ludens (the playing human), engaging in a pedagogy of play, student teachers are confronted with their own biases and naïve understandings of teaching and the profession. The excursion also creates the opportunity for potential conflict and tension, which Veresov refers to as "dramatical collisions". Such social discomfort or disequilibrium acts as a good catalyst in the journey of becoming truly inclusive practitioners. However, the excursion, in contrast to a 'real' classroom, provides a low-risk setting (laboratory) for such learning. The pedagogy of play that characterizes the excursion, furthermore provides the student-teachers with an alternative approach to the "chalk-and-talk", transmission-mode teaching and learning approaches, which a large percentage of them experienced when they themselves were school learners. In this paper, the authors disseminate findings that emerged from a qualitative inquiry into the experiences of almost 1700 NWU student-teachers who participated in the 2019 excursions. Data were collected by means of questionnaires, focus group interviews, and studying artefacts.
\end{abstract}

\section{Keywords:}

Pre-service teacher education; excursions; pedagogy of play; teacher as an inclusive practitioner

JEL Classification: 123,124 


\section{Background}

Despite the intensive educational reform since the dawn of democracy in 1994, South African school education still leaves much to be desired. The dismal state of education is portrayed both in the results of international benchmark tests such as the Trends in Mathematics and Science Study (TIMSS), and in research literature. One of the biggest issues fueling this problem, is the quality of teachers in South African schools. The Centre for Development and Enterprise (2011) and the McKinsey study (Barber \& Mourshed, 2007) make it clear that no education system can surpass the quality of its teachers. Despite the fact that South Africa boasts with an innovative and progressive school curriculum, the Curriculum and Assessment Policy Statement, which advocates for inquiry learning and the development of $21^{\text {st }}$ Century skills, the reality is that many school classrooms are characterized by transmission-mode, "chalk-and-talk" approaches. Ramnarain and Schuster (2014) have shown that many South African teachers hold the view that learners can best be prepared for summative assessment opportunities through direct instruction approaches such as traditional lecturing. Research literature therefore emphasizes the importance of both pre-service and in-service teacher education.

A problem faced in pre-service teacher education, is that first-year student teachers often enter their four years of training with very naïve understandings of the teaching profession. De Beer, Petersen and Dunbar-Krige (2012) showed that South African student teachers often enter the pre-service programme with baggage such as that the job of a teacher is to instill knowledge in learners through "chalk-and-talk" approaches. Such viewpoints stem from what Lortie (1975) refers to as the "apprenticeship of observation". Student-teachers observed (very often, not inspiring) role models during their own 12+ years of having been in school. A majority of students enter their teacher education with knowledge and views that were shaped by the teachers that they had during their own school careers. Furthermore, South Africa as a young democracy still have not succeeded in creating an integrated and equal society. Many first-year student teachers start their university education with not having had much engaged interaction with people of other race groups (De Beer, Petersen \& Dunbar Krige, 2012). South Africa, despite having abandoned its Apartheid policies, are still not an equal society, and the new "apartheid" is the socio-economic divide. This means that a large percentage of Black student-teachers come from socio-economically marginalized regions, where they attended schools where there were few, if any, White students. The demographics in the nation's schools is, however, changing, and universities have a huge task to prepare future teachers for dealing effectively with large diversity in the classroomnot just in terms of race, but also in terms of language (South Africa has 11 official languages), religion (the predominant religion is Christianity, but there are also sizeable Muslim and Hindu communities), and sexual orientation (despite the fact that South Africa's progressive constitution makes provision for gay marriages, it is often frowned upon by people, mostly due to religious beliefs).

The first-year student teacher excursion reported on in this paper, was engineered to address these perennial issues faced in pre-service teacher education. However, it is done in a "low-risk" setting for novice learning (Schön, 1987).

\section{The architecture of the educational excursion}

The North-West University has three campuses, namely the Potchefstroom campus (with predominantly White students), the Mafikeng campus (with mostly Black students), and the Vaal Triangle campus (which is probably the most representative of the three campuses, in terms of the diversity profile of the South African society). In 2019, we arranged six excursions, in which nearly 1700 student teachers participated. Each of these excursions lasted three days. The excursions each had an average of between 250 to 400 students, 
and the population at each excursion was characterized by equal representation from all three campuses (e.g. 120 student teachers from each of the sites).

This excursion is informed by social constructivist principles as explained by Vygotsky (1978). The developmental process, in Vygotsky's opinion, involves periods of relative stability, which is disrupted with 'crises'- periods of dramatic change, that shape cognitive development (Kozulin, 2002). When students board the buses on campus to travel to the excursion venue, they enter a new epistemological space (the 'crises' phase in Vygotskian parlance). During the excursion, we scaffold learning across the zone of proximal development (Vygotsky, 1978), by creating a context where student teachers are confronted by both the complexity and the "messiness" of teaching as a profession. Furthermore, they are also confronted with their own biases and stereotypes, that often result in "othering" others. We concur with Lee Shulman (2004:504) who stated that teaching is "the most frightening activity that humans have ever invented", and the excursion programme was developed to confront the student-teacher with the dilemmas of practice. Although the themes dealt with during the excursion, are also addressed in the lecture rooms on campus, we claim that the excursion provides a learning space where student teachers do not only cognitively engage with the learning material, but where they also have affective experiences. During the three-day programme, student teachers are confronted with aspects such as social justice, inclusivity, as well as more engaging pedagogies, such as play. Furthermore, the activities were design to let the student teachers reflect on their own emerging identities as future teachers.

As mentioned, we subscribe to the Vygotskyan notion that learning occurs on two levels. Firstly, meaning is constructed on a social level. Through social interaction in the activities, which all take place in small groups of five students, students jointly meander through diverse viewpoints and considerations. The groups are constituted with diversity as the main criterion, so most student teachers end up in groups of students that they have not known prior to arriving at the excursion site. In most cases, a group of five student teachers will consist of representatives from all three campuses, and a diversity of people in terms of race, language, and sometimes even religious affiliation. Since the programme entails sensitive issues, such as social justice, poverty, the HIV/AIDS pandemic and diversity (language, race, religion, sexual orientation) in the classroom, it should be expected that students would often hold conflicting views. The excursion therefore provides a unique learning space where student teachers, often outside their own comfort zones, will have to reflect on alternative viewpoints than their own. This creates the platform where "dramatical collisions" (Veresov, 2009) often occur. Veresov (2010) derives this 'dramatical collisions' from Vygotsky's love of Russian theatre. A "dramatical collision" could happen between student teachers on the excursion, just as it unfolds on stage. Veresov (2010, p. 88) makes it clear that "(s)uch emotionally experienced collisions can bring radical changes to the individual's mind, and therefore can be a sort of act of development of mental functions... without internal drama, such mental changes are hardly possible". After the activities, student teachers have to reflect on their own learning. This entails the "second plane" of learning, in Vygotsky parlance. The student teacher now has to reflect on what he/she personally has learned, either through written reflections, or by producing an artefact such as a newspaper or poster, that reflects on the learning task.

In order to break the cycle of "chalk-and-talk" teaching and learning in our classrooms, the excursion builds on a pedagogy of play. The student teachers, in homo ludens (Huizinga, 1955) [the playing human] mode, engages in learner-centred activities such as those indicated in Table 1. 
Table 1: Some of the activities in the excursion programme (this is but a sample of some of the activities. Also, every excursion has a persona of its own, and we change the programme, based on the expertise that staff members bring to each excursion).

\begin{tabular}{|c|c|c|}
\hline Learning activity & Short description of the activity & Rationale behind the activity \\
\hline $\begin{array}{l}\text { The Famine and } \\
\text { Abundance game }\end{array}$ & $\begin{array}{l}\text { Student teachers each receive } \\
\text { (randomly) a passport of a } \\
\text { country, and based on the } \\
\text { Human Development Index of } \\
\text { the country, they also receive } \\
\text { money, which they can use to } \\
\text { buy food with at the "excursion } \\
\text { shop". This results in students } \\
\text { from industrialized countries } \\
\text { buying food to their hearts' } \\
\text { desire, and students from } \\
\text { developing countries not being } \\
\text { able to buy any food. }\end{array}$ & $\begin{array}{l}\text { This activity provides an } \\
\text { opportunity for student } \\
\text { teachers to reflect on the large } \\
\text { socio-economic divide in the } \\
\text { country, with the "haves" and } \\
\text { "have-nots". Students coming } \\
\text { from a background of privilege } \\
\text { has an opportunity to (almost } \\
\text { viscerally) experience and } \\
\text { reflect on the life of the } \\
\text { destitute. The discussion } \\
\text { afterwards focuses on the } \\
\text { agency of the teacher, and } \\
\text { how to deal with the socio- } \\
\text { economic divide in the } \\
\text { classroom. }\end{array}$ \\
\hline $\begin{array}{l}\text { Shoestring-teaching: } \\
\text { building solar cookers }\end{array}$ & $\begin{array}{l}\text { Student teachers (in their } \\
\text { groups of five) have to plan } \\
\text { and build sun stoves, using } \\
\text { cheap, recyclable materials } \\
\text { such as cardboard boxes, } \\
\text { aluminum foil, plastic cling } \\
\text { wrap, duct tape, an empty cold } \\
\text { drink can, and black spray } \\
\text { paint. Water is then heated in } \\
\text { the can (within the solar } \\
\text { cooker), and after a period of } \\
\text { time, the water temperature is } \\
\text { measured. }\end{array}$ & $\begin{array}{l}\text { Many school classrooms in } \\
\text { South Africa can be described } \\
\text { as under-resourced. This } \\
\text { appeals to the agency of the } \\
\text { teacher, to improvise in terms } \\
\text { of teaching and learning } \\
\text { resources. }\end{array}$ \\
\hline HIV/AIDS activity & $\begin{array}{l}\text { Each student received two } \\
\text { glasses, filled with a liquid. } \\
90 \% \text { of the students receive } \\
\text { water (they would be 'HIV } \\
\text { negative'), whereas } 10 \% \\
\text { would receive a base solution } \\
\text { (sodium hydroxide), and the } \\
\text { latter students would be 'HIV } \\
\text { positive' (Petersen, De Beer \& } \\
\text { Dunbar-Krige, } 2011 \text { ). Students } \\
\text { are then required to exchange } \\
\text { liquids (representing 'body } \\
\text { fluids') with five other students. } \\
\text { All liquids are then tested with } \\
\text { phenolphthalein, an indicator } \\
\text { for a base solution. (It would } \\
\text { give a pink colour to a base } \\
\text { solution). Whereas only } 10 \% \\
\text { of students were 'infected' at } \\
\text { the beginning, the majority of } \\
\text { students are 'HIV positive' }\end{array}$ & $\begin{array}{l}\text { In a country where there are } \\
\text { many child-headed families, } \\
\text { where parents died due to the } \\
\text { HIV/AIDS pandemic, it is } \\
\text { important to make student } \\
\text { teachers aware of the } \\
\text { pandemic, that probably } \\
\text { influence at least one learner } \\
\text { in every classroom. However, } \\
\text { the activity is also a } \\
\text { demonstration of a pedagogy } \\
\text { of play, and afterwards a } \\
\text { discussion is held on the } \\
\text { affective affordances of such a } \\
\text { pedagogy. }\end{array}$ \\
\hline
\end{tabular}




\begin{tabular}{|l|l|l|}
\hline $\begin{array}{l}\text { Role-play of case } \\
\text { studies }\end{array}$ & after the exchanges. & \\
& $\begin{array}{l}\text { Student teachers are provided } \\
\text { with cases, which were written } \\
\text { by seasoned teachers, and } \\
\text { they then (in groups) have to } \\
\text { write screen plays, and } \\
\text { dramatize these cases. These } \\
\text { dramatized cases all portray a } \\
\text { "dilemma" that a teacher would } \\
\text { face, e.g. professional } \\
\text { boundaries, discipline issues, } \\
\text { etc. }\end{array}$ & $\begin{array}{l}\text { Groon \& Merseth (2017) have } \\
\text { shown that cases provide an } \\
\text { effective pedagogy in } \\
\text { providing student teachers } \\
\text { with more nuanced } \\
\text { perspectives on the } \\
\text { complexity of the teaching } \\
\text { profession. This 'embodied } \\
\text { cognition' activity also provide } \\
\text { the teacher educator with } \\
\text { insight into the perceptions } \\
\text { and pre-conceived ideas of } \\
\text { the students. }\end{array}$ \\
& \multicolumn{2}{|l}{} \\
\hline
\end{tabular}

\section{Methodology}

This qualitative research is part of a bigger design-based research study into the value of excursions in pre-service teacher education. The excursion was conceptualized by one of the authors (De Beer) in 2007, when he was still employed as a teacher educator at the University of Johannesburg. During the past 13 years the excursion had a rhizomic development of its own, and since 2016 the North-West University joined the University of Johannesburg in engaging first-year student teachers in such an intervention. Data used in this paper were collected from the 2019 cohort by means of questionnaires, focus group interviews with student teachers, and studying student artefacts (e.g. posters and newspapers that they compiled). Interviews were transcribed, and coding were done using the technique described by Saldana (2009), namely codes were identified; similar codes were grouped into categories, and from these categories emerging themes were derived. In this paper we highlight six predominant themes. Ethics clearance was obtained from the University.

\section{Findings}

In this paper we would like to highlight six major findings that emerged.

\section{Embarking on a journey of developing a unique and shared identity}

The development of their own and shared identities among first-year student teachers are very evident from the interview data. Firstly, many of the student teachers, at the beginning of the excursion, had under-developed (even naïve) views of themselves as teachers. Several of the students indicated in the interviews that they were not sure whether teaching is the appropriate career for them. Secondly, many of these student teachers initially experienced a feeling of discomfort, uncertainty, insecurity and even distrust, in engaging with student teachers from other race groups, religious backgrounds, and different campuses. We were pleased to see that the excursion positively changed their views on this "othering" of people. In the focus group interviews on the last day of the excursions, several student teachers commented on how they realised that they all shared an identity 'of being super-teachers'.

Many of the initial negative experiences of student teachers may be grounded in the stereotypes that the different racial groups hold of each other. The acceptance of these derogatory stereotypes, a type of knowledge, can be traced back to the former apartheid system in South Africa where a small proportion of the population (predominantly White) 
benefited from the regime at the expense of the vast majority of the rest of the population (Black, Coloured and Indian). This is the type of knowledge that Jonathan Jansen called "Knowledge in the Blood". Whereas Jansen's 2010 book defines this as the type of knowledge about the views, beliefs, values and attitudes of young white Afrikaans speaking students that was acquired from the society they grew up in, including their parents, family, friends, the schools and the churches they attended, we view such 'knowledge in the blood' as being true of all racial groupings in South Africa, as all groups experienced Apartheid in different ways. Jansen further argues that there is a tension between this type of knowledge and the knowledge they need to function effectively in a new post-apartheid democratic South Africa (Web 2011:224).

In one of the comments made by a White student, she expressed that the Black students believe that they as White students "are entitled" and that they "didn't really know what to expect". A black student commented that he was anxious to work in a group with White students, because, according to him, these white students "will always be on their own, working by themselves, you greed them they just look at you". This particular excursion took place after the 'fees must fall' campaign that was characterized by unrest where, amongst others, university property was also burned down. The following comment by one of the White students was "To be honest I did not really want to come especially when I heard Mafikeng campus is coming. Because I know you guys, there's a bit of... I don't know what to call it... "onrus" (unrest)". This student's fear may be grounded in media coverage which often portray the message that Black students are responsible for such destructive behaviour. The reflection of another Black student, who also believed that white people like to be in control, can perhaps be traced back to his father's beliefs, as he states "...my father used to say this people [white people] they like to be in control". Jansen's argument about "knowledge in the blood" has only reference to the knowledge that young white Afrikaans speaking students possess. Although the comments made by some of the White students are supportive of Jansen's argument, it may possibly also be true for other racial groups based on their belief systems mentioned above.

Although it is true that some student teachers did enter the excursion with certain stereotypes, it is also evident that not all the participating student teachers regarded these "inherited stereotypes" as barriers, but rather a challenge to find a new shared identity. This is evident in the following quotes by students: "It felt to me like although we all are different, with different cultures, we actually have the same goal in mind. We want to teach the learners". Another Black student teacher, who was expecting that the White group members will again be in control, experienced something totally different- a sense of acceptance and accommodation "But suddenly I just realised that they are like us, that we are one people".

It was clear during the focus group interviews that there was a strong realisation that, although the differences among each other (or groups) are a reality, they all do share a common goal as student teachers, which is the wellbeing of their future learners. Some of the remarks of the participants confirming this finding are "to grow young minds", and "We have it a little bit easy and they have it a little bit hard and in all it is just about teaching and love the kids", "We got here as teachers to make what- one strong bond" and yet another "It felt to me like although we all are different, with different cultures, we actually have the same goal in mind. We want to teach the learners". They realised that it is better to work together or "to beat as one" as one participant called it. One striking remark was, "You know what- a well enjoyed coffee is the one that has milk. I am the strong black coffee and they are my milk'.

Although many student teachers tended to group with people of the same campus or race group at the beginning of the excursion, it become evident (by observing the student teachers) that they learned to trust each other as they participated in the excursion activities. In this regard they actually listened, agreed or disagreed to an argument not based on the 
campus or race of fellow students, but rather agreed or disagreed to the issue under discussion. One student teacher said the following about the bush dialogues "because we as students come to sit together from different campuses and we share our different thoughts".

As the student teachers meandered through the excursion programme, they realised that, although they shared a common identity, they also have to develop their own unique identities as becoming teachers. During the activities the student teachers were constantly reminded that, if they want to become 'super teachers' (a mantra that characterised the excursion), they have to identify and nurture their own 'super powers'. 'Super power' in this regard refers to the good personal characteristics that they already possess, and that will shape their own emerging identities as future teachers. Some of these super powers include:

To be a caring motivator: "I have to be positive to my learners, I have to be there for them, they have to take me as their parent, their community leader, their pastor, their father and etc., that's what I think".

- To be patient: "So, we as the future teachers we have to be patient, we have that special room to accommodate all the differences that we might find from our classes".

- To be a lifelong learner to inform my teaching: "...I think I like to learn, I'm actually a learner, I like to learn new things", and another comment, "That we as the teachers, we must keep on studying that we don't give outdated information to our learners".

- To be a 'leader from behind': "But now I learned that I want to be a teacher, I want to lead from behind you know. It's always great when you lead the learners from behind. Let them make the mistakes, let them be on their own, then correct them whenever they fall, be that person who rescues them".

- Perseverance and determination, or to never give up on your learners: "You are making the child give up, I mean if you give up on the child, then what is the child going to do? The child is simply going to give up cause the teacher doesn't care so why must l"?

- To be analytical and reflective: "As a teacher you must be able to analyse, because I come from Limpopo and the school that I went to is a very difficult school. So if you are a teacher in that kind of context you must be able to analyse the situation and be able to come up with better solutions for learning so you need to be able to analyse and be analytical". One student teacher referred to her own agency even though she felt uncomfortable: "I normally don't enjoy camps at all. I've always had bad experiences with camps, so when my friend said to me; "come with me on this camp", I thought to myself I want to be the best teacher I can be, so I said; "yes I will come".

\section{Student teachers' realization of the complexity of teaching}

Lee Shulman (2004:504) said, after thirty years of teaching experience, that "I have concluded that classroom teaching... is perhaps the most complex, most challenging, and most demanding, subtle, nuanced, and frightening activity that our species has ever invented". Alex Quigley (2014) regard Shulman's quote as one of the best synopses of teaching and describes the complexity of teaching as "It captures the brilliant, maddening and humbling complexity of the education of a child. The pursuit of answers and certainty amidst such complexity appears to be a fool's errand". Very few people will disagree that teaching is indeed a complex activity and it is therefore not strange that many neophyte teachers struggle to cope with the demands of the profession in the first couple of years as a teacher. Research also highlights the so called theory-practice divide (Kessels \& Korthagen 1996), and that many novice teachers feel that their university education did not adequately prepare them for the 'coalface of practice'. The bottom line remains that a number of newly trained teachers can't cope with the demands and leave the teaching profession because of the numerous difficulties they face such as feelings of frustration, loneliness and loss of self- 
confidence (Robertson-Kraft \& Duckworth 2014). According to Amir, Mandler, Hauptman and Gorev (2017:231) one of the reasons for this appears to be that undergraduate teacher training institutions focus more on the theoretical-academic aspects than on a more practical and behavioural approaches to teacher education. It is therefore an obligation of all tertiary institutions that its undergraduate teacher programme curricula are designed in ways to educate student teachers holistically in order for them to be agents who can cope with the demands of their chosen profession. We believe that the educational excursion can play a role to better prepare student teachers for the demands that they will face as neophyte teachers.

It may be easy to talk about the complexity of teaching, but what does it entail and how did the excursion sensitise the student teachers about these matters? In an editorial overview about the complexity of teaching, Livingston (2017) include the following elements of a teacher's work, namely the learning needs of learners, learners with learning difficulties, choice of suitable assessment and teaching learning strategies, the use of technology to enhance the learning environment, the subject content and its specific requirements, the particular groups of learners to be taught, and their contexts. In this paper the focus is on the diverse context of the South African classroom characterised by significant racial, ethnic, linguistic and other forms of diversity (Reygan \& Steyn 2017). The other forms of diversity include religion, sexual orientation and the unequal socio-economic backgrounds of learners. The same authors argue that "there is a growing call in South Africa for new approaches to education that engage in a nuanced way with issues of power, privilege and difference" ( $p$. 69). The authors of this paper belief that to expose student teachers during an island situation (excursion) to actual diversity, social justice and inequality issues of a typical South African classroom, can be regarded as such a new approach.

One student teacher participating in the focus group interviews expressed himself as follows: "What I have experienced is that we will be going to different schools were we will meet learners who are from different backgrounds with different issues. So, we as the future teachers have to be patient, we have that special room to accommodate all the differences that we might find from our classes". One student particularly made the following comment about the famine and abundance game (see Table 1): "I got a whole new perspective on these things. I said to myself there really is people out there with problems or unhappily exposed to this". 'These things' in the quote refers to privilege and the realisation that there might be learners in her classroom one day from absolutely poor backgrounds thinking of where their next plate of food will come from while others may dream of a next overseas holiday. Regarding this matter another student said "To me the highlight is there are so many people in this country that don't even have a house to live in and let alone something to cook".

In one of the activities, the HIV/AIDS simulation game (see Table 1), the student-teachers were exposed to the consequences of the HIV/AIDS pandemic and how it influences the classroom. During the evening activity, the "bush dialogues", the student teachers debated the challenges teachers face in dealing with AIDS in the classroom, as a type of reflection on the HIV/AIDS simulation game. One particular student, from a Catholic background, was very adamant that the AIDS pandemic can be prevented if "people stop to sleep around" (promiscuous behaviour). Her frustration was evident in her voice and body language and most of the other students at the fire (during the "bush dialogues") did not appreciate her tone and condemnation. However, during the focus group interviews it was clear that this experience forced her to be more accommodative about these types of personal matters when se said "I should have phrased it better. I sounded very bitchy in the way I said that. It was a flop on my side. I now know I have to be more diplomatic when I speak, consider everybody else, what they might say". This student teacher came to realise that the same myriad of perspectives will characterise her classroom one day, and that she should be mindful to respect other points of view as well. 
Some other realizations by the student teachers were, amongst others, that a lack of teaching resources should not be regarded as an excuse or barrier, because "you don't need expensive equipment to make certain things". This student referred to the activity where they built sun stoves from cheap materials, also known as 'science-on-a-shoestring approaches'. The student teachers also recognized that, although teachers have relative freedom with regard to using certain teaching- learning strategies in their classrooms, that they have to operate within the boundaries of the school and management, the parents/community and the department of basic education. These role-players may have an influence on their teaching practice. One student teacher voiced this as follows: "Then it draw me back to say well, somewhere somehow, what is happening in a political context? It can influence us in the education system, because if we have a government leadership that is malfunctioning therefore it will affect us in the education department".

\section{Awareness of the necessity of critical reflection}

In order for (beginner) teachers to cope with the demands of the teaching profession they continuously and critically have to reflect on their own practices in order to find solutions to the challenges they might face. Mathew, Mathew and Peechattu (2017:126) argues that if teachers will grow professionally by constantly looking into their own actions and experiences. The same authors claim that reflective practices "is a process that facilitates teaching, learning and understanding, and it plays a central role in teachers' professional development". Faghihi and Sarab (2016:57) state that reflective practises should be an integral element of teacher pedagogy. The excursion provides student teachers with a learning space in which they can develop skills to become critical and reflective practitioners. One of the student teachers noted: "I was surprised that none of my perceptions and prejudices about people of other race groups held any water. On this camp, I made new friends across colour lines. It made me realize that, as a truly inclusive teacher, I should do self-assessment. Am I a racist? How are my own viewpoints shaped by my personal environment and friends? This camp initiated a personal journey for me, that I need to embark on".

\section{Student teachers reported on how the excursion raised an awareness for the joys of teaching, and enkindle a passion for teaching}

One of the student teachers, during a focus group interview, stated that the excursion made her more aware of the impact that a teacher can have on learners: "Teaching was not my first option; I wanted to become a social worker, but my marks were not good enough. Something woke up inside me during the excursion...I now want to be a super-teacher. The children that we see on the streets...they are often there because of teachers who failed them".

A consistent theme emerging from our data, is that many of the student teachers entered the pre-service teacher education programme with teaching not being their first choice. However, in many of these students a passion for teaching were enkindled during the excursion, and provided them with the peace of mind that they made the right career choice.

Another student (Adam Ngwenya, who we need to acknowledge, as the title of our paper was derived from his statement) said the following:

"As a teacher I hold a seed in my hand. The truth is that I actually hold a forest in my hand. The seeds should produce more seeds". 


\section{The excursion provides student teachers with a greater sensitivity, understanding and respect for diversity in the South African classroom}

Although diversity and inclusivity is one of the hallmarks of pre-service teacher education at the NWU, it is often a cognitive learning experience, and not an affective experience. De Beer, Petersen \& Dunbar Krige (2012) have shown that the excursion, with its different dynamics compared to the formal classroom, is effective in sensitizing student teachers towards cultural diversity. Student teachers are provided the opportunity during the excursion programme to identify their own biases and prejudices, which might hamper their professional development to become 'super teachers'. (One of the motivational speakers that we invite to address the students during the excursion, $\mathrm{Dr}$ Francois Naude, a previous National Teachers Award winner, coined the term 'superteacher' while he addressed the students during the excursion, arguing that, like any of the super-heroes, every teacher should also have a rare 'super-power'. We were rather stunned at how this discourse became the vortex of discourse during the excursion amongst the student teachers).

One of the student teachers (a White male student from the Potchefstroom campus) commented in a focus group interview: "To be honest I did not really want to come especially when I heard Mafikeng campus is coming. Because there is a bit of unrest (the student actually used an Afrikaans word 'onrus' in his otherwise English dialogue) between Potchefstroom and Mafikeng. But when I came here, there were no hostility from any side, I was so surprised. It felt to me like, although we are different, with different cultures, we actually have the same goal in mind. We want to teach the learners."

Another student dovetailed on this statement, and said the following: "What was nice for me on the excursion, is that we had the opportunity to speak to people from other cultures. I don't think that every white person feels the same, but you guys (look at the discourse of "othering"; this White student is now addressing the Black students who were part of the focus group interview) are very very loud. On the bus you were so loud, and we were more reserved, and I always thought it was rude to be so loud. When I spoke to some of the Black students here, I found out that in your culture it is rude to be soft spoken, as people might think that you are gossiping. So for me I had to understand where I come from and where you come from, it's just wonderful. So, now I understand that we are different and that we can accommodate each other".

In response to these statements by White students, one of the Black Mafikeng campus students responded as follows: "I expected that there will be competition between the Potchefstroom campus students, and us. There's that thing of how Potchefstroom students talk, "we are from the main campus". I then feel as "OK, I am just a Mafikeng, Setswana speaking student. They don't see us as a university that is productive. However, we developed a good relationship with them on this camp."

\section{The students reported on an appreciation for the learner-centred teaching methods that they engaged with during the excursion, e.g. the pedagogy of play}

Student teachers often enter the pre-service teacher education programme with "baggage" collected over 12 years of having been in school, where they often observed bad teaching practices. Many of them experienced predominantly transmission-mode teaching and learning (e.g. "chalk-and-talk"). During the excursion the focus is on engaging as Homo ludens (Huizinga 1955) in learner-centred activities, characterized by 
a pedagogy of play. Student teachers reflected positively on this: "Wow. I for the first time engaged in the World Café, and it was so interesting. I want to do this in my classroom one day". Another student teacher reflected on the pedagogy of play used in the Famine and Abundance game: "It was interesting to see how emotional the students became during the game. It showed me how powerful such an activity can be for learning. It was an eye opener".

\section{Conclusion}

De Beer (2017) refers to Schön (1987) that speaks of "a low-risk setting for novice learning", and the former author claims that such an educational excursion provides such a low-risk setting for learning. The excursion becomes a "laboratory" where student teachers come to confront their own naïve ideas about teaching, and the biases and prejudices that they might hold, and they also get the opportunity to engage with new pedagogies. However, this learning occurs in a "safe zone", and not in the coalface of teaching, where children are involved. The "dramatical collisions", in Veresov (2009) parlance, can be powerful catalysts for individual learning and professional development, but it takes place in a setting where school learners are protected from negative consequences. Our data shows that the excursion, as a "low-risk learning space", provides the opportunity for student teachers to develop more nuanced views of the teaching profession, and to set professional development goals for themselves. Above all, it sensitizes student teachers to diversity, inclusion and social justice, that is so needed in South Africa's fragile democracy.

\section{Acknowledgement}

This work is based on a research project supported by the National Research Foundation (NRF) of South Africa (Grant Number 114333). The grant holder acknowledges that opinions, findings and conclusions or recommendations expressed in this publication generated by the NRF-supported research are those of the author, and that the NRF accepts no liability whatsoever in this regard.

\section{Bibliography}

Amir, A., Mandler, D., Hauptman, S., \& Gorev, D., 2017. Discomfort as a means of preservice teachers' professional development - an action research as part of the 'Research Literacy' course. European Journal of Teacher Education, 40(2):231-245.

Barber, M. and Mourshed, M., 2007. How the world's best-performing schools systems come out on top. McKinsey \& Company.

Centre for Development and Enterprise., 2011. Value in the classroom: the quantity and quality of South Africa"s teachers. CDE In Depth Number 11. Johannesburg: CDE.

De Beer, J., 2017. The zone of proximal teacher development under the microscope: Reflections of a teacher educator. Proceedings of the Fourth IISES Teaching and Education Conference, Venice, April 2017, 13 - 27.

De Beer, J., Petersen, N., \& Dunbar-Krige, H., 2012. An exploration of the value of an educational excursion for pre-service teachers. Journal of Curriculum Studies 44(1), 89 110.

Faghihi, G., \& Sarab, M.R.A. 2016. Teachers as reflective practitioners: a survey on iranian english teachers' reflective practice. The Journal of Teaching Language Skills, 7 (4), 57-86. 
Gravett, S., De Beer,J., Odendaal-Kroon, R., \& Merseth, K., 2017. The affordances of case-based teaching for the professional learning of student-teachers. Journal of Curriculum Studies, 2017, DOI:10.1080/00220272.2016.1149224.

Huizinga, J., 1955. Homo ludens: A study of the play element in culture. Boston: Houghton Mifflin.

Kessels, P., \& Korthagen, F., 1996. The relationship between theory and practice: Back to the classics. Educational Researcher 25, $17-22$.

Kozulin, A., 2002. Sociocultural theory and the mediated learning experience. School Psychology International 23(1), 7 - 35.

Livingston, K. 2017. The complexity of learning and teaching: challenges for teacher education. European Journal of Teacher Education, 40(2):141-143.

Lortie, D., 1975. Schoolteacher. Chicago: University of Chicago Press.

Mathew, P., Mathew, P., \& Peechattu, P. 2017. Reflective practices: a means to teacher development. Asia Pacific Journal of Contemporary Education and Communication Technology (APJCECT), 3(1):136-131.

Petersen, N., De Beer, J., \& Dunbar-Krige, H., 2011. Use of a simulation game for HIV/AIDS education with pre-service teachers. African Journal of AIDS Research 10(1), $73-81$.

Quigley, A. 2014. Is Research Evidence in Education the Answer? The confident teacher.

https://www.theconfidentteacher.com/2014/09/research-evidence-edcuation/ Date of access: 31 May 2019.

Ramnarain, U. \& Schuster, D., 2014. The pedagogical orientations of South African Physical Sciences teachers towards inquiry or direct instructional approaches. Research in Science Education 44, 627-650.

Reygan, F. \& Steyn, M., 2017. Diversity in Basic Education in South Africa:

intersectionality and Critical Diversity Literacy. Africa Education Review, 14(2):68-81.

Robertson-Kraft, C., \& Duckworth, A., 2014. True Grit: Trait-level Perseverance and Passion for Long-term Goals Predicts Effectiveness and Retention among Novice Teachers. Teachers College Record (1970), 116(3).

Saldana, J., 2009. The coding manual for qualitative researchers. Los Angeles, CA, SAGE.

Schön, D.A., 1987. Educating the reflective practitioner. San Francisco, Jossey Bass.

Shulman, L.S., 2004. The wisdom of practice: Essays on teaching, learning and learning to teach. San Francisco, Jossey-Bass.

Veresov, N., 2009. Emotions, experiencing, and cultural development: Vygotsky's unfinished project. From http://www.unil.ch/webdav/site/psydesc/shared/Nikolai Veresov. 
Veresov, N., 2010. Introducing cultural historical theory: main concepts and principles of generic research methodology. Accessed from http://psyjournals.ru/files/32913/kip 20104 Veresov.pdf

Vygotsky, L.S., 1978. Mind in society. Harvard University Press.

Web, V. 2011. Knowledge in the blood (review). Tydskrif vir letterkunde, 48(2):224-228. 